\title{
Relatos de fugida na literatura galega e portuguesa: Estudo comparativo do imaginário e espaço comum em Cinco Dias, Cinco Noites e Amigo medo
}

\author{
María Colom Jiménez
}

Recibido: 12 de xuño de 2020 / Aceptado: 15 de setembro de 2020

Resumo. Os relatos de exílio e fugida de um país para o outro por motivos políticos e os períplos transfronteiriços têm sido objeto de representação literária habitual. O presente trabalho pretende analisar, através de uma aproximação comparativa e tendo em conta contextos históricos e culturais semelhantes, as novelas curtas Cinco Dias, Cinco Noites (1975), de Manuel Tiago, e Amigo medo (2002), de Xavier López Rodríguez, como relatos de fugida que também podem ser inseridos dentro das narrativas de denúncia. Igualmente é estudada a construção do espaço e do imaginário comum galego-português nestes relatos, assim como os recursos narrativos e as temáticas principais dos relatos de fugida surgidos a partir da segunda metade do Século XX.

Palabras-chave: relatos de fugida; estudo comparativo; narrativa galega; narrativa portuguesa; espaço e imaginário comum; século XX.

\section{[es] Relatos de huida en la literatura gallega y portuguesa: Estudio comparado del imaginario y espacio común en Cinco Dias, Cinco Noites y Amigo medo}

Resumen. El exilio y las huidas de un país al otro por motivos políticos y los periplos transfronterizos han sido objeto de representación literaria habitual. Este trabajo pretende analizar, a través de un acercamiento comparativo y teniendo en cuenta unos contextos históricos y culturales similares, las novelas cortas Cinco Dias, Cinco Noites (1975), de Manuel Tiago, y Amigo medo (2002), de Xavier López Rodríguez, como relatos de huida inseridos dentro de las narrativas de denuncia. Asimismo, se estudia la construcción del espacio y del imaginario común gallego-portugués en estos relatos, así como los recursos narrativos que se encuentran inseridos dentro de la temática de los relatos de huida surgidos a partir de mediados del siglo XX.

Palabras clave: relatos de huida; comparatismo; narrativa gallega; narrativa portuguesa; espacio e imaginario común; siglo XX.

\section{[en] Escape Short Narratives in Galician and Portuguese Literature: Comparative Study of the imagery and common space in Cinco Dias, Cinco Noites and Amigo medo}

Abstract. Fleeing, exile and migration from one country to another for political reasons and cross-border journeys have been object of literary representation. This study aims to analyse, from a comparative point of view, the short narratives Cinco Dias, Cinco Noites (1975), by Manuel Tiago, and Amigo medo (2002), by Xavier López Rodríguez, as short fleeing narratives, inserted within denunciation narratives. The study focuses on the construction of a galicianportuguese space and the imagery in these novels, as well as, relating to the literary elements used in the novels which exemplify the themes of escape narratives from the last half of the 20th Century.

Keywords: Flight or Escape Narratives; Comparative Study; Galician Literature; Portuguese Literature; common space; 20th Century.

Sumário. 1. Breve contextualização histórica. 2. Resumo panorâmico da narrativa de denúncia. 3. Temas tratados nos relatos de fugida da literatura galega e portuguesa. 4. Imaginário e espaço comum em Cinco Dias, Cinco Noites e Amigo medo. 5. Considerações finais. 6. Referências bibliográficas.

1 Universidad Complutense de Madrid. Departamento de Estudios Románicos, Franceses, Italianos y Traducción Correio-e: mcolomji@ucm.es 
Referência normalizada: Colom Jiménez, M. (2020): "Relatos de fugida na literatura galega e portuguesa: Estudo comparativo do imaginário e espaço comum em Cinco Dias, Cinco Noites e Amigo medo", em Madrygal. Revista de Estudios Gallegos 23 Núm. Especial, pp. 79-88.

¿Pode un home pasar a maior parte da súa vida amordazado polo medo? Non debe, pero pode, claro que pode. (Amigo medo, 2002: 11)

Com 19 anos incompletos, André viu-se forçado a emigrar. Arranjaram-lhe dinheiro, deram-lhe um endereço para o Porto e disseram-lhe que ai se resolveria a passagem de fronteira para

Espanha. As coisas não foram, porém, assim tão fáceis.

(Cinco Dias, Cinco Noites, 1996: 9)

\section{Breve contextualização histórica}

Pode dizer-se que o Século XX, dentro do espaço geográfico europeu, esteve fortemente marcado não só pelos horrores da Primeira e Segunda Guerra Mundial, mas também pelas ideologias e as consequências socioculturais motivadas pelas ditaduras fascistas que se foram instalando ao longo de todo o território. $\mathrm{O}$ nosso pequeno cantinho da Europa, a Península Ibérica, mesmo sem ter tido uma implicação explícita nas guerras mundiais, não conseguiu evitar também sucumbir perante as correntes políticas que assediavam a Europa nesse período. Nesse sentido, quer a Espanha, quer Portugal, tiveram regimes políticos bastantes semelhantes, tendo vivido ambos os países em ditaduras fascistas. Apesar do facto de que Portugal não sofreu a desgraça de uma guerra civil, os lusos passaram pelo que conhecemos hoje como a ditadura fascista mais longa da Europa do Século XX, facto que, como é de supor, marcou fortemente o imaginário da literatura portuguesa a partir da segunda metade do Século. Como aponta João de Melo no seu ensaio Um Olhar sobre a Literatura Portuguesa (2004), embora o processo político na Espanha e em Portugal fosse bastante semelhante, os autores portugueses encontraram ademais vários problemas paralelos que afetaram ao país não apenas politicamente, mas também socialmente e culturalmente: ditadura, guerras coloniais e perda de colónias:

O país, apesar de pequeno e de secundarizado em quase todos os contextos e padrões europeus, nem por isso deixou de dar aos seus escritores um conjunto de experiências de vida a que nem sempre foi possível ter acesso nos grandes países da Europa Ocidental. Espanha viveu um processo político e social algo paralelo ao de Portugal, mas bem distinto nos seus momentos cruciais. Os escritores de meu país e da minha geração conheceram a ditadura de Salazar e Caetano, estiveram em África numa das três frentes da guerra colonial (...), participaram na queda do regime, na revolução, viveram a mudança radical do país «mental» em que tinham sido educados, assistiram ao «fim da História» portuguesa e ao «regresso» a uma Europa remota (...). (Melo 2004: 2-3)

Portugal sofreu quarenta e um anos de ditadura (1933-1974), e António de Oliveira Salazar (1889-1970), que foi adaptando o seu discurso político em função das circunstâncias, manteve sempre pareceres em comum com outros regimes fascistas europeus. O Estado Novo (1933-1974) foi criado em 1933, com o próprio Salazar nomeado primeiro-ministro de Portugal. Foi então que começou uma forte campanha de propaganda em favor de Salazar e do Estado Novo, focalizada essencialmente em questões como a estabilidade económica e nacional, a segurança social e a paz nas colônias. Historicamente, pode destacar-se 1934 como o ano em que se deu início à censura em Portugal, graças à criação da Secretaria de Propaganda Nacional, facto que nesse então solidificou a censura literária e jornalística do país. A propaganda nacionalista e a censura tiveram deste modo um grande impacto na população portuguesa como refere Nascimento Santos:

Convém lembrar que para a execução desse projeto nacionalista/expansionista necessitava-se um estado forte, autoritário e controlador. A combinação desses elementos resultou na censura a todos os meios de comunicação veiculados na metrópole e nas colônias, garantindo assim, a discussão e publicação apenas do que fosse de interesse do Estado. (2009: 46)

Como aconteceu em outros países da Europa e também na Espanha, a censura em Portugal levou ao exílio, prisão ou morte de muitos jornalistas, escritores e intelectuais da época. Como não poderia ser de outra maneira, encontramos na literatura portuguesa e na literatura espanhola, a partir desse momento inúmeros textos de inconformidade e inquietação para com a ditadura, "a literatura sempre teve um importante papel de testemunho e de memória desse tipo de atrocidades ao oferecer vivências afetivas de realidades" (Schollhammer, 2015: 39). No âmbito da literatura portuguesa, os numerosos exemplos literários de mal-estar e 
denúncia contra o regime podem ser encontrados quer no género narrativo, quer na poesia; por exemplo, o contista José Rodrigues Miguéis, exiliado em Nova Iorque, escreve nas notas para a terceira edição da sua narrativa Onde a Noite se Acaba (1946):

O escritor de hoje, que viveu quarenta anos, pode-se dizer que viveu muito como homem, e pouco como escritor. Nascido com o século, embalaram-no sonhos, promessas, ilusões; criança assistiu ao regicídio, ao delírio heroico da propaganda republicana, ao aluir miseríssimo dum torno, ao que se julgava o fim de um mundo; e entre os ferimentos (ainda hoje em carne viva) da reforma ortográfica, passou de enunciar os reis das várias dinastias, a citar os corifeus do novo regime. (1960: 223)

Neste mesmo sentido, uma década antes, Fernando Pessoa escreve a respeito de Salazar diversos poemas nos quais já se pode considerar palpável o tom de crítica e denúncia feito por parte do poeta lisboeta. Podemos pôr como exemplo o poema "COITADINHO" escrito em 1935, e que não seria publicado até 1979:

Coitadinho

do tiraninho!

Não bebe vinho.

Nem sequer sozinho...

Bebe a verdade

E a liberdade.

E com tal agrado

Que já começam

A escassear no mercado.

\section{(...)}

Que isto consola

E nos dá fé.

Que o coitadinho

Do tiraninho

Não bebe vinho,

Nem até

Café.

(vv. 1-26; Pessoa 2008: 324).

De novo, em tom de crítica e denúncia, encontramos em 1950, da mão de Miguel Torga, o poema "Dies Irae" do volume Cântico do Homen:

Apetece, cantar, mas ninguém canta.

Apetece chorar, mas ninguém chora.

Um fantasma levanta

A mão do medo sobre a nossa hora.
Apetece gritar, mas ninguém grita.

Apetece fugir, mas ninguém foge.

Um fantasma limita

Todo o futuro a este dia de hoje.

Apetece morrer, mas ninguém morre.

Apetece matar, mas ninguém mata.

Um fantasma percorre

Os motins onde a alma se arrebata.

Oh! Maldição do tempo que vivemos,

Sepultura de grandes cinzeladas,

Que deixam ver a vida que não temos

$\mathrm{E}$ as angústias paradas!

(Torga 1985: 119)

\section{Resumo panorâmico da narrativa de de- núncia}

A partir do início da década de 40, começaram já a surgir com empenho alguns testemunhos de denúncia na literatura portuguesa. No entanto, como é de supor dado o controle severo de censura e a problemática do exílio e da falta de liberdade de expressão, não será até depois dos anos 70 -passada a Revolução de 25 de abril de 1974- que podemos notar um incremento considerável no que diz respeito à temática literária relacionada com a denúncia e desconformidade contra o regime. Como aponta Reis, em 1974 finaliza o que tinha sido um "tempo político e cultural algo incaraterístico", depois do qual "a liberdade de expressão e a descolonização permitem rever ficcionalmente os dramas individuais e coletivos":

Em termos mais específicos (e ainda assim inevitavelmente sintéticos), deve dizer-se que a Revolução de 25 de Abril de 1974 pôs termo a um tempo político e cultural algo incaracterístico. (...) a abertura política trouxe consigo consequências diversas, quase sempre constituindo um potencial de tematização literária que a ficção muitas vezes acolheu: a liberdade de expressão e a descolonização permitiram rever ficcionalmente os dramas individuais e coletivos da guerra colonial (...). (Reis 2004: 16)

No caso da literatura galega, como menciona Vilavedra (2011), chegaram tarde à narrativa as obras que relatam acontecimentos históricos relacionados com a guerra civil espanhola:

El tema de la guerra civil entró tardíamente en nuestra narrativa, y lo hizo por medio de tres exiliados. La publicación en 1957 de Non agardei por ninguén de Ramón de Valenzuela es sólo aparentemente precoz pues lo cierto es que el libro, publicado en la editoral bonaerense $\mathrm{Ci}$ tania, dirigida por Luís Seoane, tuvo realmente 
una limitadíssima difusión en la Galicia interior, donde no circuló hasta su reedición en Akal en 1989. De la década de los 70 son $O$ silencio redimido de Silvio Santiago (1976) y O siñor Afranio ou como me rispei das gadoupas da morte de Antón Alonso Ríos (1979). Estos escritores compartían experiencias vitales determinantes en sus biografías pues los tres vivieron el conflicto bélico en primera persona (bien en el frente, bien como 'fuxidos') y los tres tuvieron como única salida el exilio sudamericano. (2011: 4)

Como analisa Vilavedra, foi a partir do final dos anos 50 que começaram a surgir relatos de experiência, mas como no caso da literatura portuguesa, não será até a década dos anos 70 que encontremos também na literatura galega um maior número de novelas dedicadas à temática de denúncia e de memória frente aos horrores da guerra.

Com respeito às diferentes temáticas encontradas nas obras narrativas a partir de meados dos anos 70, como aponta Dantes (2012), o escritor Álvaro Cardoso Gomes no seu livro A voz itinerante (1993), nomeia a "atuação crítica a respeito de factos históricos" como uma das características mais latentes da prosa portuguesa contemporânea:

Não se trata, porém, de uma literatura acomodada a formas romanescas tradicionais: a confiança no romance não descartou, em absoluto, o questionamento de suas formas e limites, bem como dos temas desenvolvidos, principalmente dos enredos históricos. Álvaro Cardoso Gomes identifica, como a principal característica da prosa portuguesa contemporânea, a atuação crítica a respeito de factos históricos, através de um "distanciamento irônico" e de uma "projeção do imaginário sobre o real". (Gomes 1993: 85, apud Dantes 2012: 139)

Como se observa, constatamos que é a partir da década de 1940 que a narrativa em língua portuguesa começa gradualmente a mudar o seu registro e apela fortemente contra o autoritarismo, mediante uma feroz denúncia social e política, servindo como relato de testemunho e de memória histórica. Como já foi apontado, notaremos como no género narrativo as histórias focadas no tema do exílio, a repressão ou a fuga, e a memória histórica, não verão realmente a luz, na sua maioria, até fins da década de 70 ou princípios da década de 80 , que será quando comecem a surgir em maior número os romances históricos. Foi igualmente nesse momento, e de maneira paralela, que a narrativa galega inicia o seu tratamento de factos históricos nos relatos que são escritos por autores de uma geração posterior à guerra civil:

Y si dije antes que la memoria 'rescata' es porque prácticamente todas las novelas a las que me voy a referir parten de un hecho real, que reconstruyen con mayor o menor fidelidad, pero raramente nos encontramos ante casos de ficción o invención total. El valor de 'verdad' de lo real parece legitimar el tratamiento de un tema que no parece aceptar la trivialización que puede suponer lo ficcional. (...)

Tras ese prudente alzar el velo del silencio, el ritmo de publicación de novelas sobre el tema se aceleraría progresivamente. Pero no serían ya sus protagonistas los que se encargarían de narrar la guerra sino la generación siguiente, la de los nacidos después de 1930 que, o bien aún no habían nacido cuando estalló el conflicto, o bien eran demasiado niños como para tener recuerdos personales de aquellos días. (Vilavedra 2011: 3-5)

Sendo que no presente estudo, o tema que nos ocupa está mais focalizado nas narrativas dedicadas ao tema do exílio ou fugida, convém destacar que é a partir dos anos 80 que a literatura portuguesa -pós-modernista- abrange não só temas históricos relacionados com a ditadura, mas também relacionados por vezes com crítica pós-colonial e pós-imperial. Inúmeras narrativas de denúncia política e social surgem da mão de alguns dos mais proeminentes autores portugueses da segunda metade do Século $\mathrm{XX}$.

Como resultado estamos perante narrativas de memória histórica que flutua entre o real e o imaginário, entre a verdade e a ficção, entre a autobiografia e a invenção, como analisa Dantes "(...) e a consequente constatação de que a literatura não (re)cria a realidade, não traz ninguém ou nenhum facto de novo à vida, mas, apesar disso, e através da memória, é possível que a ficção construa ou se movimente por entre as "sombras» de certos "mapas»" (2012: 145). A grande maioria destas obras, como afirma Rocha no seu estudo de 2003, têm como foco comum a reflexão sobre os temas de autoridade, identidade (individual e nacional) e liberdade:

(...) a literatura portuguesa contemporânea constrói representações de aspetos da história recente do país, vinculados à ditadura salazarista e aos seus mecanismos de manutenção, como repressão política e cultural, censura e propaganda ideológica. A memória literária da ditadura opera por três grandes linhas temáticas: 
autoridade, identidade e liberdade, significativas para a leitura crítica de obras que formam um corpus que se constitui como uma contranarrativa performativa, desafiadora dos discursos pedagógicos e totalizantes do poder. (2003: 29)

José Saramago (1922-2010) junto com António Lobo Antunes (1942-), são dois exemplos de autores portugueses que destacam durante estas décadas com romances históricos de temática de denúncia, em obras como Levantando o Chão (1980), História do Cerco de Lisboa (1989) ou Ensaio sobre a Cegueira (1995), de Saramago, ou Memória de Elefante (1979), As Naus (1998), Livro de Crónicas (1998) e $O$ Esplendor de Portugal (1997), de Lobo Antunes, entre outras. Também é importante notar as obras de autores como José Cardoso Pires (1925-1998) em O Dinossauro Excelentíssimo (1972) ou A República dos Corvos (1988), e Álvaro Guerra (1936-2002) em Memória (1971) ou Café República (1982). A denúncia política e social encontrá-la-emos também em obras de Mário Cláudio (1941-) em As Máscaras de Sábado (1976), Lídia Jorge (1946-) em Notícia da Cidade Silvestre (1984), Manuel Alegre (1936-) em O Canto e as Armas (1970) e João de Melo (1949-) em A Memória de Ver, Matar e Morrer (1977) (lista em Melo 2004: 3-4). É precisamente neste contexto literário que encontramos o romance Cinco Dias, Cinco Noites de Manuel Tiago, publicado em 1975.

No caso da literatura galega, cabe destacar as seguintes obras escritas num contexto parecido ao da narrativa portuguesa já mencionada: O silencio redimido de Silvio Santiago (1976), O siñor Afranio ou como me rispei das gadoupas da morte de Antón Alonso Ríos (1979), Os mortos daquel verán de Carlos Casares (1987), Scórpio de Ricardo Carballo Calero (1987), Visperas de Claudia de Manuel Guede (1987), Francisco Fernández del Riego $O$ cego de Pumardedón (1992), Entre fronteiras de Xavier Alcalá, As rulas de Bakunin (2000) de Antón Riveiro, Os libros arden mal (2006) de Manuel Rivas, Non volvas (2000) de Suso de Toro, ou Aqueles anos do Moncho (1977) de Xosé Neira Vilas, entre muitas outras (lista em Vilavedra 2011: 4-8).

\section{Temas tratados nos relatos de fugida da literatura galega e portuguesa}

Nas prosas que relatam os périplos de fugida, encontramo-nos perante narrativas que se desenvolvem dentro dum âmbito temático muito diverso, mas que por sua vez se encontram situadas num momento histórico concreto. Os enredos destas prosas giram em torno à crítica social e política, à descolonização e aos seus efeitos: guerra, exílio, autoridade, liberdade de expressão, crítica de factos históricos, repressão, fuga, memória, identidade e liberdade. É importante ter em conta que, durante este período, surgirá também uma mudança de perspetiva no que denominamos como narrativa de viagens. Na literatura em língua portuguesa, observamos nas narrativas de viagens anteriores ao Século $\mathrm{XX}$, a predominância de protagonistas que servem como exemplo do heroísmo do indivíduo que retorna à sua terra natal depois de ter viajado pelo mundo, navegando em busca do desconhecido. O tema comum e central nestas obras é contar histórias de heroísmo e glória, quer individual, quer nacional. Estes relatos e histórias de viagens individuais ou coletivas vão mudar consideravelmente de perspetiva durante e após a ditadura. Como destaca Vieira "Si el mar estaba abierto a las carabelas para sembrar la gloria de Portugal mundo afuera, ahora las aguas se cierran atrás de los que regresan y obligan a la nación a rever su historia, sus mitos y sus verdades" (2009: 203). Os escritores já não se vão centrar em relatar aventuras e viagens de índole heroica e de glória individual ou nacional, e a viagem passa a tornar-se num itinerário de exílio ou fuga, muitas vezes individual e não coletivo.

Nestas narrativas destaca a necessidade e o esforço de sobrevivência em oposição ao desejo de conquista do desconhecido. Os protagonistas destas novelas e contos fogem aterrorizados de um espaço a outro, e o que prevalece é a sua luta pessoal pela sobrevivência e subsistência. O foco temático será, nestes casos, muito diferente: os indivíduos que retornam -os que têm a sorte de voltar- regressam à sua terra natal carregados de traumas próprios das vivências de exílio e a adaptação ao novo espaço torna-se complexa. Esta sensação de não pertencer a lado nenhum é precisamente o caso do protagonista de "Regresso à Cúpula da Pena", um dos contos da coletânea Léah e Outras Histórias (1973) de José Rodrigues Miguéis, história na qual a personagem principal narra o seu regresso a Lisboa após ter passado vinte anos exiliado noutro país, encontrando-se extremamente frustrada por se sentir estrangeiro na sua própria cidade:

Tinha partido daqui vinte anos antes, guardando disto tudo uma imagem estática, cristalizada, que só para mim era viva e actual, pois conservá-la era preservar a própia pele e manter-me 
idêntico a mim mesmo; e via agora com espanto que o que trazia comigo era apenas um ramalhete de flores murchas, um cadáver conservado de que urgia libertar-me. A minha vida tinha sofrido um corte em dado instante do passado, era como um still de cinema, antiquado e risível. (...) Sofria, assim, como um indivíduo que, olhando-se no espelho, não reconhece a sua própia imagem. (....) Alguém! Alguém que me reconhecesse e restituísse, me reatasse na continuidade minha e das coisas. (Não como aquele ardina da véspera, a quem eu tinha pago o jornal com uma moeda de prata: o garoto olhou para o dinheiro, assombrado, levou dois dedos à boina, fez uma cabriola e piscou-me o olho: «OK, American!» - Vinte e tal anos de amor fiel, e vem um garoto esperto, um génio de observação, e chama-me estrangeiro com todas as letras!). (1975: 107-108)

Vieira, referindo-se à obra As Naus de António Lobo Antunes, explica perfeitamente este giro temático e o novo significado dado ao uso do espaço na prosa contemporânea:

El gran navegante portugués no puede ocupar más el mismo espacio en la patria contemporánea. (...). Diferentemente de Los Lusíadas, en el cual el mar es un espacio fundamental (no podemos olvidarnos que el mar funcionaba como símbolo de un mundo a ser conquistado por los portugueses), en Las naves, la trama se irá a centrar en las tierras. (...). Si el mar estaba abierto a las carabelas para sembrar la gloria de Portugal mundo afuera, ahora las aguas se cierran atrás de los que regresan y obligan a la nación a rever su historia, sus mitos y sus verdades. (2009: 201-203)

O presente trabalho insere os relatos de fugida dentro do âmbito de estudo do que se denomina como narrativas de denúncia ou romance histórico, posto que os relatos de fugida são precisamente relatos (ficcionados ou autobiográficos) de acontecimentos históricos reais propagados pelas guerras e ditaduras do Século XX. Neste sentido, sendo a Galiza e Portugal irmãos fronteiriços, as fugidas de um território para o outro foram constantes durante este período histórico, como também foi sempre constante o convívio dos habitantes das cidades fronteiriças entre Espanha e Portugal, "Estou afeito a falar o que falamos aquí, que ten tanto de portugués coma de galego, e non estou seguro de que vostede entenda ben" (Amigo medo, 2002: 24). Podemos considerar estes relatos e os estudos dedicados à comparativa de ambas as literaturas como mais um exemplo de convivência entre galegos e portugueses, relação que se descreve à perfeição em Amigo medo:
Poderá atopar vostede algo estraño que dese por sentado que un rapaz de quince anos, os que tiña daquela, soubese o camiño da Moimenta, un lugar doutro país. Daquela, era ben certo que eu ainda non coñecía Ourense nin Zamora, as cidades que temos máis próximas; (...) pero o certo é que sabía da Moimenta todo o que había que saber, desde os camiños posibles, o das lagoas e o da beira río, ata os comercios nos que se mercaba mellor cada cousa que adoitabamos subir de Portugal. (...) Daquela había moita relación, moito contrabandeo desde Portugal. (López Rodríguez 2002: 36-37)

As principais linhas temáticas que podem ser estudadas através da análise das narrativas de denúncia e, por tanto, também podem ser encontradas nos relatos de fugida ou inclusive nas histórias mais centradas na experiência do exílio, podem ser analisados e estudados através da análise comparativa dos rasgos comuns, quer no contexto da literatura galega, quer no da literatura portuguesa, pois no que diz respeito aos relatos de fugida, ambas as literaturas estão consequentemente em contacto, como veremos no estudo comparativo das obras $\mathrm{Cin}$ co Dias, Cinco Noites e Amigo medo. Nos romances de fugida encontramos linhas temáticas concretas que ajudam a identificar e a inserir estas narrativas num contexto histórico determinado. Em primeiro lugar, existe nestas obras uma forte crítica a respeito de factos históricos que, como veremos nos relatos a tratar, são factos históricos muito concretos e relatados de maneira verídica. Os factos históricos formam parte direta do discurso narrativo, "vendo a foto que vén nunha das follas que me deixou vostede, cústame recoñecer nela o xeneral que guiei a Portugal" (López Rodríguez 2002: 20). Neste mesmo sentido, notamos como os aspetos de convivência, a universalidade da vida cotidiana, os dramas e as misérias diárias dos indivíduos se encontram sempre à sombra de um contexto histórico também muito real:

Desagradaram nitidamente um ao outro. Ao Lambaça, que julgara ter de fazer passar a fronteira a algum importante dirigente, André parecia uma criança insignificante e inofensiva, diminuindo, quase ao ridículo, a incumbência. A André o aspeto e expressão de Lambaça avivavam desconfiança e prevenção acerca de seu caráter. (Tiago 1994: 11-12)

Devemos também destacar que uma das questões principais expostas nas obras de fugida é o tratamento minucioso de sentimentos relacionados com a solidão, inadequação, frustração e o medo à morte dos protagonistas. As 
personagens destas obras estão em constante confrontação com sentimentos de confusão, angústia e medo. A afirmação da identidade individual das personagens que vai evoluindo ao longo do relato, no fundo reivindica também a identidade de toda uma cultura, o medo e a frustração de todo um povo. Logo, o medo é o sentimento mais palpável nos romances de fugida, algo que não se sente da mesma forma na literatura de exílio ou nas obras de viagem de conquistas.

O peor de todo é ter que recoñecer que non hai razóns suficientes para explicar o meu silencio, como non sexa o costume de calar, que botou raíces fondas en todos nós.

$\mathrm{O}$ único que me mantivo tanto tempo sen falar con sinceridade foi o medo. É o que eu creo, de verdade. ¿Toda a vida? Si. Poderiamos dicir que o medo decidiu quedar a vivir comigo. (López Rodríguez 2002: 15)

Nestes novos relatos, durante a viagem não se conquista nada, há uma inadaptação ao próprio espaço geográfico porque o mais importante é fugir desse espaço, foge-se da morte. $\mathrm{O}$ exílio físico das personagens pode dar lugar por vezes ao exílio interior como consequência do medo à morte, mas também pela dificuldade de adaptação a ambientes desconhecidos.

\section{Imaginário e espaço comum em Cinco Dias, Cinco Noites e Amigo medo}

As obras Cinco Dias, Cinco Noites (1975) e Amigo medo (2002) foram publicadas com 27 anos de separação, no entanto ambas relatam os acontecimentos de uma viagem de fugida, tendo elementos comuns que podem ser trazidos à luz numa análise comparativa. No caso de Cinco Dias, Cinco Noites o protagonista, André, vê-se obrigado a fugir de Portugal e cruzar a fronteira para a Espanha por causas políticas.

A ação do romance Cinco Dias, Cinco Noites começa a desenvolver-se no norte de Portugal, em Vila Velha de Raia, no final da década de 1940 . O texto conta com poucas personagens, sendo o mais importante André, um jovem lisboeta de dezanove anos, que foge da prisão durante a ditadura de Salazar e quer cruzar a fronteira para se exiliar na Espanha. Para fugir, contrata os serviços de Lambaça, um contrabandista que o ajudará a cruzar a fronteira por Trás-os-Montes. Por várias circunstâncias, o jovem André mostra antipatia constante para com o Lambaça e sente por ele uma profunda rejeição (sendo ambos portugueses, mas de um status social bastante diferenciado). À medida que o relato se desenvolve, o leitor percebe que as aventuras e experiências partilhadas entre ambas as personagens na viagem farão que comecem a ganhar confiança e respeito um pelo outro. Além do plano de cariz histórico-social do romance, exemplificado pelas circunstâncias e temáticas da fugida e posterior exílio do jovem André, a história enfatiza no facto de que dois homens tão diferentes em personalidade, educação e experiências, podem chegar a tornar-se amigos "camaradas" por causa das duras circunstâncias que são forçados a partilhar e viver em conjunto.

No caso do romance Amigo medo, o protagonista -com apenas 15 anos- é obrigado a acompanhar e ajudar o general Gómez Caminero (general republicano) a cruzar a fronteira entre Espanha e Portugal em julho de 1936. A história é contada pelo protagonista que, já estando numa fase muito avançada da vida, relembra enquanto narra de uma forma íntima e pessoal um processo de autoconciliação com o seu próprio passado e a sua própria vida.

Os protagonistas de ambas as novelas vêem-se obrigados de maneira diferente a conviver durante um espaço muito curto de tempo com os elementos que acompanham psicologicamente as fugidas: a incerteza, a ansiedade, a solidão e, principalmente, o medo. No caso específico de Cinco Dias, Cinco Noites e Amigo medo, também encontramos como os factos históricos se entrelaçam com a memória histórica dos acontecimentos próximos de maneira ficcional, e até, em alguns casos, da própria experiência histórica e memória dos autores. Ambas as novelas podem ser consideradas narrativas históricas, no entanto, são relatos onde se utiliza um episódio histórico concreto para relatar amplos temas relacionados com a condição humana. Assim, o momento histórico é apenas o contexto temporal onde se desenvolvem estes relatos que, no fundo, realçam as "paixões e emoções humanas", como afirma Xavier López numa entrevista sobre a sua obra Amigo medo, ao ser perguntado o que supõe para um autor escrever sobre um episódio histórico, "Lo que hice fue partir de un hecho histórico puntual para hilvanar una historia donde se reúnen muchas pasiones y emociones humanas":

Toda novela histórica requiere una dura labor de documentación previa. En mi caso, nunca quise hacer una novela histórica. A la hora de escribir Amigo miedo nunca me planteé reconstruir al detalle aquella época, ni siquiera los sucesos en 
que me baso y que, por otra parte, constituyeron un minúsculo grano de arena en la contienda. Lo que hice fue partir de un hecho histórico puntual para hilvanar una historia donde se reúnen muchas pasiones y emociones humanas: amor y amistad, venganza, ruindad y, sobre todo, miedo, una historia desde la que se traslada una invitación a la reflexión sobre cuestiones éticas. Lo de participar en la recuperación de la memoria histórica me vino sin buscarlo, pero me siento orgulloso de mi modesta aportación a un reto que todavía requiere muchos esfuerzos. (López Rodríguez, entrevista com Libreria Cazarabet)

Logo, a viagem dos protagonistas de ambos os relatos ocorre durante um contexto histórico determinado e as dificuldades com que se deparam surgem precisamente por causa dos problemas que esse contexto concreto supõe. No entanto, os perigos que correm durante a viagem são paralelos às aprendizagens vitais de autoconhecimento e de convivência com os outros que estas novelas pretendem destacar, revelando alguns dos aspetos mais íntimos e sinceros da natureza humana e também verdades universais: os segredos bem guardados, os primeiros amores, a família, as amizades, os costumes do quotidiano, as relações humanas, as relações do homem com a natureza, a culpa, o medo, a vingança, etc. "Dándolle voltas na cabeza ó muito que me custou decidirme a contarlle a miña historia co xeneral Caminero, cadroume pensar que os segredos son coma árbores que prenden logo e son máis dificiles de arrancar cada día que pasa (López Rodríguez 2002: 28).

Contan que en España houbo moita fame, sobre todo nos anos corenta. Aquí, por sorte, nunca nos faltou qué comer. (...) Agora, coma daquela, as maiores fames son case sempre consecuencia das guerras. Fames que seica chegan a matar ata a un cento de personas por día, no caso de Sudán. Máis das que quedamos neste lugar. (Ibid.: 60)

(...) André lembrou-se da fome passada nos dias anteriores.

- Não seria melhor guardarmos o resto para logo? - disse. - Ou temos onde ir jantar?

De boca cheia, o Lambaça fitou o companheiro com os olhitos negros e observadores e como única resposta cortou novo bocado.

- Você é de fazer perder a paciência a um santo - insistiu André. - Não ouve o que lhe digo? (Tiago 1994: 82)

É interessante destacar como a viagem -algo tão importante para a sobrevivência dos protagonistas de ambas as novelas- se desenvolve num espaço temporal muito curto, cinco dias no caso de Cinco Dias, Cinco Noites, e um dia no caso de Amigo medo. A temporalidade reduzida e expressada através de acontecimentos rápidos é utilizada pelos autores em ambos os romances como ferramenta narrativa para recriar os momentos de tensão e medo próprios das fugidas.

Andaram umas horas de comboio, comeram a merenda e, por volta do meio-dia, largaram o comboio numa pequena vila alegrada de sol. Aí deviam apanhar uma camioneta, que seguia por estrada fronteiriça. Começava a haver vigilância e era necessário evitar os perigos. A camioneta passava por uma aldeia onde estava instalado um posto. Segundo dizia o Lambaça, era frequente pedirem ali os documentos aos passageiros. (Tiago 1994: 15)

Non sei qué hora sería. O sol xa se achegaba ó lombeiro, pero estabamos no mes de xullo - para nós Santa Mariña, como xuño era San Xoán-e aínda ía unha calor abafante. Camiñabamos cara ó poñente e eu sentía a calor na cara. Nas costas, sen embargo, sentía que a miña suor era fría como a neve. - ¡Camiña con toda a présa que poidas! - oín dicir tras de min, e souben que o xeneral falara por primeira vez. Tiña medo de que se nos fixese de noite antes de chegar á raia con Portugal, supuxen. (López Rodríguez 2002: 42)

Neste curto espaço temporal, os acontecimentos e sentimentos encontrados com os que os protagonistas se veem obrigados a conviver fazem com que a viagem funcione também como um itinerário pessoal de autoconhecimento, aprendizagem e reflexão: "Un acaba por acostumbrarse a todo, supoño. $\mathrm{O}$ instinto de seguir comendo manda máis cá cabeza. Esa debe de ser a cualidade máis importante, a que mellor explica a supervivencia das persoas: que tamén somos animais" (Ibid.: 67).

Os cenários retratados nos romances foram selecionados à perfeição para que o leitor seja capaz de mergulhar nessas paisagens fronteiriças entre a Espanha e Portugal. O sentimento de angústia e medo (sentido pelo protagonista nos dias da fugida) não é somente palpável nos diálogos ou reflexões dos dois protagonistas, mas também na caracterização do espaço, muitas vezes escuro e hostil, "começavam as curvas de uma longa subida e adivinhavam-se adiante montanhas desertas. A demora da camioneta começou a inquietá-lo. Viria realmente por ali? (...) Andando mais de um quilómetro pela estrada deserta, parou, ofegante e desanimado" (Tiago 1994: 19). Além da escolha inteligente dos cenários (paisagens), devemos 
destacar o uso de luz-não luz nos momentos de angústia e pânico:

O jovem desaparecerá por uma porta ao fundo, que rangera empenada. A velha adormecera encostada à mesa. Junto à máquina de costura, voltada agora para a luz, a outra mulher costurava em silêncio. André não conseguia distinguir-lhe o rosto. Apagada na sombra do lenço, só de quando em quando lhe dava com os olhos a luzir na sua direcção, para logo fugirem de novo. Retinha a ideia do rosto da mulher desfigurado pela cólera (...) Já 1 da madrugada o Lambaça voltou com o da cicatriz. Este trazia agora um lampião, que colocou sobre a mesa e começou a acender, depois de ter tirado a chaminé ao candeeiro. A luz embaciou e avermelhou. (Ibid.: 35)

Do mesmo modo, o som também joga um papel principal nos relatos. Na fugida, a atenção constante ao âmbito sonoro é importantíssima para a sobrevivência das personagens. Quando lemos os romances, um dos aspetos que rapidamente capta a nossa atenção é a análise minuciosa dos sons por parte dos protagonistas. O sentido da audição durante a fugida tem de ser o mais desenvolvido, enfatizando deste modo o sentimento de preocupação e medo durante a viagem. Através dos pensamentos de André ouvimos os comboios, os autocarros, as crianças a brincar e a rir, o deserto da estrada, o isqueiro que dá lume aos cigarros de Lambaça, etc.

Como já foi mencionado, nos romances de fugida os sentimentos de frustração, exílio interior, solidão e inadaptação dos protagonistas são uma constante, mas devemos destacar que será o medo o sentimento mais recorrente e palpável nestes relatos, e são múltiplos os momentos vividos com medo à morte durante a viagem: "Eles tiñan armas, e viñan con elas desde Brumoso. Nós tiñamos o medo. Por iso acudiamos ás manifestacións. Por iso levantabamos o brazo dereito, coa man ben aberta e coa palma cara a baixo, cando nos reclamaban o saúdo oficial" (López Rodríguez 2002: 91-91).

Guiei os forasteiros cagado de medo, teño que recoñecerllo, porque eu ben lles vira as armas. Coido que agachaban as pistolas e os uniformes nas alforxas, pero tanto Caminero coma os seus axudantes levaban ben ás vistas outras armas longas. Supoño que eran fusís, os famosos Máuser, pero non quita que levasen tamén al- gunha metralladora. Non sei. Só lembro as culatas, que abondaban para me dar ben de medo. (Ibid.: 73-74)

Saiba vostede que o medo foi tamén o meu principal compañeiro na viaxe co xeneral Caminero. Coido que xa llo dixen. Porque era rapaz de abondo para ter medo de calquera cousa, pero tamén mozo de abondo para pensar nas consecuencias que a miña acción, por obrigada que fose, me podería acarrexar no futuro. ¡Axudar a un xeneral Republicano, case nada! (Ibid.: 93)

\section{Considerações finais}

No presente estudo foi examinado como os contextos históricos comuns vividos pela Espanha e Portugal no Século XX trazem consigo como consequência rasgos comuns também na área da literatura. $\mathrm{O}$ exílio, a imigração e/ou os périplos de fugida transfronteiriços serão tema recorrente na literatura da pós-guerra ou no romance histórico. Neste contexto, foi estudado como os relatos dedicados à temática de fugida começaram a aparecer com força durante os anos $70 \mathrm{em}$ ambas as línguas, e existe uma mudança na temática e no itinerário da literatura de viagens a partir desse momento. Estas narrativas já não giram em torno a temas de índole heroica e de conquista, mas pelo contrário, narram viagens individuais nas que prevalece o medo, a frustração, a solidão e a constante luta pela sobrevivência. Os heróis destes relatos conquistam a sua própria sobrevivência e lutam contra as consequências e os traumas causados pelo medo à morte durante toda a sua vida, sendo o autoconhecimento e a superação um dos tópicos principais destes relatos.

Os estudos de índole comparativa entre a literatura galega e portuguesa são essenciais para analisar e perceber um espaço e imaginário comum que sem dúvida enriquece ambos os mundos. Como foi analisado no estudo das obras Cinco dias, Cinco Noites e Amigo medo, não só encontramos semelhanças no tratamento das personagens, mas também na análise do espaço geográfico e na utilização do tempo. Observamos como os indivíduos protagonistas destes relatos sofrem as mesmas inquietudes e traumas enquanto lutam por sobreviver em constante contacto com a natureza ou com os espaços fronteiriços comuns. 


\section{Referências bibliográficas}

Dantes, Gregório F. (2012): “A 'segunda história': considerações sobre romance português contemporâneo”, Revista Investigações 25/1, pp. 137-162, https://periodicos.ufpe.br/revistas/INV/article/view/1533.

Gomes, Álvaro Cardoso (1993): A voz itinerante. São Paulo: Edusp.

Libreria de Cazarabet: Entrevista a Xavier López Rodríguez, http://www.cazarabet.com/conversacon/fichas/fichas1/amigomiedo.htm [consulta: 11/05/2020].

López Rodríguez, Xavier (2002): Amigo medo. Vigo: A Nosa Terra.

Lourenço, Eduardo (2007): O Labirinto da saudade. Lisboa: Gradiva.

Melo, João de (2004): "Um Olhar sobre a Literatura portuguesa". Embaixada de Portugal em Madrid, http:// cvc.institutocamoes.pt/reccultura/litport espanha.pdf [consulta: 11/05/2020].

Miguéis, José Rodrigues (1960): Onde a Noite se Acaba. Lisboa: Editorial Estampa.

— (1975): Léah e outras Histórias. Lisboa: Editorial Estampa.

Nascimento Santos, Jeane de Cassia (2009): "Literatura colonial portuguesa: Espaço, poder e imperialismo", Revista Fórum Identidades 3/5, pp. 45-59.

Pessoa, Fernando (2008): Obra essencial de Fernando Pessoa: Poesia do Eu. Lisboa: Assírio \& Alvim.

Reis, Carlos (2004): “A ficção portuguesa entre a Revolução e o fim do século", Scripta (Belo Horizonte) 8/5 (2 ${ }^{\circ}$ sem.), pp. 15-45, http://periodicos.pucminas.br/index.php/scripta/article/view/12566.

Rocha, Carla (2003): “A memória literária da ditadura: autoridade, identidade, liberdade", Revista Ipotesi 7/2, pp. 29-39.

Schollhammer, Karl Erik (2015): “A história da ditadura”, Lua Nova (São Paulo) 96, pp. 39-54, https:// www.scielo.br/pdf/ln/n96/0102-6445-ln-96-00039.pdf.

Tiago, Manuel (1994): Cinco Dias, Cinco Noites. Lisboa: Ed. Avante.

Torga, Miguel $\left(1985^{2}\right)$ : Antologia poética. Coimbra: Gráfica de Coimbra.

Vieira, Fabricio (2009): "El viaje como proceso de re-visitación histórica: Las Naves de António Lobo Antunes", Cuadernos Literarios 5/8, Cuadernos de Viaje, Universidad Católica, sedes Sapiential, pp. 199-203.

Vilavedra, Dolores (2011): "Memoria y postmemoria: la elaboración literaria de la Guerra civil en la literatura gallega", en Raquel Macciuci (dir.), Memoria Académica del II Congreso Internacional de literatura y cultura Española contemporáneas, vol. 2, http://www.memoria.fahce.unlp.edu.ar/trab_eventos/ ev.2803/ev.2803.pdf. 